\title{
Autoimmunity in differentiated thyroid cancer: Significance and related clinical problems
}

\author{
Ulla Feldt-Rasmussen, Åse Krogh Rasmussen
}

Department of Medical Endocrinology, Rigshospitalet, National University Hospital, Copenhagen, Denmark

\begin{abstract}
Coexistence of differentiated thyroid cancer (DTC) and thyroid autoimmune diseases could represent a mere coincidence due to the frequent occurrence of autoimmunity, but there may also be a pathological and causative link between the two conditions. The coincidence of DTC with Hashimoto's disease has been variably reported at between 0.5 and $22.5 \%$ and of DTC with Graves' disease between 0 and $9.8 \%$. In this review available evidence for thyroid autoimmunity in DTC is summarized and it is concluded that thyroid cancer does coexist with thyroid autoimmunity, implying that patients treated for autoimmune thyroid diseases should have a careful follow-up. Furthermore, the presence of thyroglobulin antibodies ( $\mathrm{TgAb})$ in patients with DTC may limit the use of serum thyroglobulin as a tumor marker due to methodological problems in the determination of serum thyroglobulin. However, in such cases serial TgAb measurements may be used as a surrogate marker for recurrence of thyroid cancer during the long-term monitoring of DTC patients.
\end{abstract}

Key words: Autoimmune thyroiditis, Graves' disease, Hashimoto's thyroiditis, Thyroglobulin antibodies, Thyroid cancer

\section{INTRODUCTION}

While being the most frequent endocrine malignancy, differentiated thyroid carcinoma (DTC) is rare, accounting for approx. $1 \%$ of cancers. The various thyroid autoimmune diseases, on the other hand, are all very frequent in most populations and the occurrence of thyroid autoantibodies, e.g. thyroid peroxidase (anti-TPO) and thyroglobulin antibodies

\section{Address for correspondence:}

Ulla Feldt-Rasmussen, Department of Medical Endocrinology PE 2132, Rigshospitalet, National University Hospital, Blegdamsvej 9, DK-2100 Copenhagen, Denmark, Tel.: +45354 52399, Fax: +45354 52240, e-mail: ufeldt@rh.dk Received 15-12-09, Revised 10-02-10, Accepted 10-03-10
( $\operatorname{Tg} \mathrm{Ab}$ ), in the circulation varies from 10 to $25 \%$ in the adult population, depending on age and gender, with the highest prevalence occuring in postmenopausal women. Environmental factors such as iodine and selenium intake as well as radiation from nuclear power plants, atomic bombs or therapeutic applications can affect both cancer and immunity of the thyroid gland.

Coexistence of thyroid cancer and thyroid autoimmune diseases may thus arise by mere coincidence due to the frequent occurrence of autoimmunity, but it has been hypothesised that there might be a pathological and causative link between these two conditions. The frequent occurrence of thyroid 
autoimmunity in a given population is also true for patients with differentiated thyroid carcinoma, in whom the presence of $\mathrm{TgAb}$ at approximately $25 \%$ is higher than in the general population. ${ }^{1}$ This has raised three important issues: 1) coexistence of thyroid autoimmunity is associated with a better or worse prognosis of thyroid carcinoma, 2) the presence of $\mathrm{Tg} \mathrm{Ab}$ hampers the use of serum thyroglobulin $(\mathrm{Tg})$ as a tumour marker, which is otherwise the keystone in current guidelines, ${ }^{2,3}$ and 3) serial measurements of serum $\operatorname{Tg} \mathrm{Ab}$ can be useful as a surrogate marker in the follow-up of patients with thyroid carcinoma that are $\mathrm{Tg} \mathrm{Ab}$ positive.

The aim of the present review is therefore to summarise available evidence for thyroid autoimmunity in differentiated thyroid cancer and to put it into perspective in relation to its significance in modifying the outcome of DTC.

\section{DO THYROID CANCER AND AUTOIMMUNITY COEXIST?}

The coexistence of Hashimoto's thyroiditis (HT), which is a chronic autoimmune disease, and differentiated thyroid carcinoma was first described by Dailey et al in $1955 .{ }^{4}$ Since then, numerous authors ${ }^{5-27}$ have reported coexistence of the two diseases, ranging from 0.5 to $30 \%$ (Table 1). In one of the recent studies, ${ }^{26} 28.2 \%$ coexistence was reported, most frequently encountered in a nodular rather than a diffuse variant of HT. A meta-analysis conducted by Singh et $\mathrm{al}^{23}$ demonstrated that the incidence rate of HT was 2.8 times higher in patients with papillary thyroid carcinoma (PTC) than in subjects affected by benign thyroid diseases. Furthermore, in patients with thyroid carcinoma, the incidence rate of HT was 1.99 times higher in those with PTC than in subjects with other histopathological forms of thyroid carcinomas. Albeit indirectly, these results suggest that patients with HT might well present a stronger predisposition towards the development of papillary thyroid cancer. This hypothesis was reinforced by the fact that a large number of molecular studies have shown the presence of mutation products of the oncogenes RET/PTC-a specific genetic alteration in PTC patients-in HT without clinically manifest thyroid dysfunction. ${ }^{28}$ Several studies involving the expression of $\mathrm{p} 63$ proteins, ${ }^{29}$ which generally intervene in the differentiation processes of the stem cells and which are not present in normal thyroid tissue, have shown a higher expression of such proteins in many cases of HT and of PTC. Recently, Larson et $\mathrm{al}^{30}$ reported that in their patients population who had undergone thyroidectomy in the period from 1987 to 2002, those with HT were three times more likely to have thyroid cancer. Additionally, increased phosphorylated Akt, Akt1 and Akt 2 expression was noted in regions of HT and thyroid cancer compared with regions of normal surrounding thyroid tissue. These studies have thus been interpreted as a further indication that there might be a link between the two diseases, while they also suggest possible molecular mechanisms for thyroid carcinogenesis.

It must be underlined however that, the published studies on the coexistence of the two diseases (Table 1) are retrospective and had applied variable histological methodology and definitions. Moreover most of the series were small and heterogeneous with a high risk of selection bias. The studies of biomolecular similarities have not provided documentation for accuracy of the methodology used, and one might suspect that the sensitivity of the genetic methods gives rise to false-positive findings. Hence, although these two diseases of the thyroid have many morphological, immunohistochemical ${ }^{31}$ and, more importantly, biomolecular features in common, the pathological significance and possible clinical implications of any correlation between them are not clear.

Thyroid cancer, in particular the papillary type, coexisting with Graves' disease (GD) has recently been extensively reviewed by Belfiore et al..$^{32}$ The coexistence has been variably reported to range from $0 \%$ to $9.8 \%$. The reasons for these discrepancies are unclear and may include differences in the genetic background and/or unidentified environmental factors. It must be considered, however, that all these studies are retrospective and might cover a very long period during which the criteria for patient selection (i.e. systematically operated GD patients vs. GD patients operated for a nodule), the extension of thyroidectomy and the accuracy of pathological examination have changed significantly. In a recent multicentre study carried out in Europe (557 consecutive patients who underwent surgery for GD in the period 1991-1997), 
Table 1. Hashimoto's Thyroiditis (HT) coexisting in patients with thyroid carcinoma (often papillary (PTC)), or vice versa (PTC in HT). The publication by Singh et $\mathrm{al}^{23}$ represents a meta-analysis demonstrating that HT was seen 2.8 times more often in PTC and patients with HT had PTC twice as often as expected. All other studies were retrospective. The study by McKee et a ${ }^{18}$ was based on fine needle aspiration cytology and all other studies on surgery.

\begin{tabular}{|c|c|c|c|c|}
\hline Author & $\begin{array}{c}\text { Coexistent HT in } \\
\text { PTC/PTC in HT (\%) }\end{array}$ & $\begin{array}{l}\text { Number of investigated } \\
\text { patients with PTC/HT }\end{array}$ & Control group & Significance* \\
\hline Dailey et al $1955^{4}$ & $23.3 / 12.6$ & $150 / 278$ & none & NA \\
\hline Pollock and Sprong $1958^{5}$ & NA/11.5 & $\mathrm{NA} / 52$ & none & NA \\
\hline Meier et al $1959^{6}$ & $<1 / \mathrm{NA}$ & $65 / \mathrm{NA}$ & none & NA \\
\hline Woolner et al $1959^{7}$ & $\mathrm{NA} / 3.0$ & $\mathrm{NA} / 605$ & none & NA \\
\hline Schlicke et al $1960^{8}$ & $8.1 / 8.7$ & $111 / 103$ & none & NA \\
\hline Shands $1960^{9}$ & $\mathrm{NA} / 6.8$ & $\mathrm{NA} / 44$ & none & NA \\
\hline Chesky et al $1962^{10}$ & $5.7 / 11.1$ & $141 / 432$ & none & NA \\
\hline Crile and Hazard $1962^{11}$ & $\mathrm{NA} / 0.5$ & $\mathrm{NA} / 222$ & none & NA \\
\hline Hirabayashi and Lindsay $1965^{12}$ & $38.8 / 22.5$ & $436 / 752$ & goitre & Yes \\
\hline Holmes et al $1977^{13}$ & $\mathrm{NA} / 3.3$ & $\mathrm{NA} / 60$ & none & NA \\
\hline Figg et al $1978^{14}$ & 19.1/NA & $105 / \mathrm{NA}$ & none & NA \\
\hline Ott et al $1985^{15}$ & $\mathrm{NA} / 32$ & $\mathrm{NA} / 146^{* *}$ & none & NA \\
\hline Ott et al $1987^{16}$ & $38 / 23$ & $161 / 267$ & goitre & Yes \\
\hline Eisenberg et al $1989^{17}$ & $10.8 / \mathrm{NA}$ & $120 / \mathrm{NA}$ & none & NA \\
\hline McKee et al $1993^{18}$ & $\mathrm{NA} / 10$ & NA/115 & none & NA \\
\hline Sclafani et al $1993^{19}$ & $\mathrm{NA} / 17$ & $\mathrm{NA} / 48$ & none & NA \\
\hline Okayasu et al $1995^{20}$ & $63 / \mathrm{NA}$ & $626 / \mathrm{NA}$ & foll ad & Yes \\
\hline Schסffler et al $1998^{21}$ & $10.9 / \mathrm{NA}$ & $92 / \mathrm{NA}$ & none & NA \\
\hline Loh et al $1999^{22}$ & 20.3/NA & $631 / \mathrm{NA}$ & none & NA \\
\hline Singh et al $1999^{23}$ & $14.7 / \mathrm{NA}$ & $388 / \mathrm{NA}$ & none & NA \\
\hline Kebebew et al $2001^{24}$ & $30 / \mathrm{NA}$ & $136 / \mathrm{NA}$ & none & NA \\
\hline Tamimi $2002^{25}$ & $58 / \mathrm{NA}$ & $50 / \mathrm{NA}$ & foll ad & Yes \\
\hline Cipolla et al $2005^{26}$ & $26.7 / 27.6$ & $71 / 47$ & goitre & Yes \\
\hline Kurukahvecioglu et al $2007^{27}$ & 18.6/NA & 199/NA & none & NA \\
\hline
\end{tabular}

$\mathrm{NA}=$ not available; Foll ad = follicular adenoma; ${ }^{*}$ presence or absence of statistically significant difference between studied patient population and control group and with a p value of 0.05 ; ${ }^{* *}$ Hashimoto's thyroiditis + solitary cold nodule

differentiated thyroid cancer was found in 21 patients (3.8\% of all patients and $15 \%$ of patients with a nodule). Tumour size ranged from 2 to $25 \mathrm{~mm}$ and only four tumours were palpable. Although further studies comparing GD and controls are needed, it seems that not only palpable nodules but also small non-palpable nodules are more frequent in GD patients than in euthyroid subjects and that GD is associated with de novo nodule formation, indicating that only a small proportion of these lesions progresses to a clinical disease. As with Hashimoto's thyroiditis, most of the published studies are either retrospective or case presentations.

Apart from the above-mentioned data on the coexistence of HT and PTC, possible mechanisms could include any type of stimulation of the thyroid gland that might lead to growth and subsequent malignancy such as thyrotropin (TSH), TSH receptor stimulating antibodies (TSAb), or cytokines produced by infiltrating inflammatory cells. ${ }^{33}$ On the other hand, 
TSH is not elevated in all patients with Hashimoto's thyroiditis. Co-existence of Hashimoto's thyroiditis with thyroid carcinoma has also been described in the euthyroid variant, and a demonstrated association between serum TSH levels and differentiated thyroid cancer did not involve a relationship with thyroid autoantibodies. ${ }^{34}$

\section{DOES RADIATION INDUCE THYROID AUTOIMMUNITY?}

It is well substantiated that irradiation to the thyroid gland in childhood is associated with a very increased risk of papillary thyroid cancer ${ }^{35}$ However, it is not established if irradiation in adulthood is associated with an increased risk of thyroid cancer and, very probably, a much longer follow-up period is necessary to exclude this possibility.

A possible effect of irradiation on thyroid autoimmunity is controversial. Although one study has described an increased risk of thyroid autoimmune disease in children living around Chernobyl at the time of radiation, ${ }^{36}$ other studies have failed to demonstrate an increased autoimmunity related thyroid dysfunction. ${ }^{37-40}$ Nevertheless, some studies seem to indicate that exposure to radiation during childhood was associated with a dose-dependent development of thyroid autoantibodies (anti-TPO), but not thyroid dysfunction. ${ }^{40}$ This was not the case in a very long-term follow-up in Japan of individuals exposed at the end of the second world war (1945), in whom only an increased risk of thyroid benign and malignant nodules was seen but neither autoimmune disease nor presence of thyroid autoantibodies was demonstrated. ${ }^{41}$ One of the important caveats in such cross-sectional epidemiological studies is selection of a representative control group, both in terms of iodine intake, gender, age, genetic constitution, etc., and this has unfortunately not been easy to carry out. Whether the presence of thyroid autoantibodies reflects a chronic destructive inflammatory infiltration which will eventually lead to autoimmune disease is at present unknown. In a normal adult population without radiation exposure, the rate of development of autoimmune disease in persons with autoantibodies varies with the gender and the level of serum TSH from $5-26 \%$ per year. ${ }^{42}$
Although radioiodine therapy for GD has been suspected of giving rise to cancer development, it seems to be a safe treatment not associated with a significant increase in total cancer mortality. ${ }^{32}$ It might, however, be associated with an increased incidence of thyroid cancer, though this is not really substantiated by available studies. Mortality studies, on the other hand, might underestimate the real incidence of thyroid cancer, which has an indolent course in most cases. Also, these studies do not indicate whether a possible increase in thyroid cancer incidence is due to the carcinogenic effect of radioiodine or is, at least partially, due to late growth of small carcinomas already present and overlooked at the time of radioiodine administration to the GD patients. Nonetheless, these data underline the need to evaluate accurately the existence of thyroid nodules before treating a GD patient with radioiodine. Finally, autoimmune thyroid disease has been identified as an occupational hazard, as described by Volzke et $\mathrm{al}^{43}$ and Davis et al. ${ }^{44}$

\section{DIAGNOSING THYROID CANCER IN THE PRESENCE OF THYROID AUTOIMMUNITY}

The diagnosis of thyroid cancer in the presence of thyroiditis and thyroid autoantibodies is very difficult. A study using fine needle aspiration ${ }^{45}$ in such situations has recently been published and, although the authors claim that there could not be false positive results, they on the other hand acknowledge that true HT combined with thyroid carcinoma is not easy to distinguish from lymphoid infiltration induced by and surrounding a thyroid cancer. ${ }^{46}$ They further suggested that a definite histological diagnosis was also necessary. Therefore, while the authors avoided a selection bias, present in many other studies, by using series of only surgical specimens, they introduced another bias due to insufficient cytological methodology. Kollur et $\mathrm{al}^{47}$ as well as many others have described histology and fine needle aspiration retrospectively in patients with HT aiming at diagnosing concomitant thyroid cancers in a palpable nodule. They described both false-positive and false-negative outcomes and concluded that diagnosis of follicular neoplasia is difficult in the presence of follicular-cell pleomorphism and/or moderate to excessive numbers of lymphocytes. While the aspiration on and around the thyroid 
nodule might help in sampling, it could also lead to false-negative results. In a retrospective Japanese study of 2167 patients, the prevalence of papillary thyroid carcinoma was estimated to be $5.5 \%$ of the 523 patients with HT and $3.3 \%$ in the non-Hashimoto patients. On ultrasonography, not only absence of psammoma bodies but also dense calcifications in patients with HT suggested the presence of PTC. The ultrasonography findings were, however, not diagnostic and it was therefore considered by the authors that it is important to make a careful examination if thyroid carcinoma is suspected in patients with HT because HT presents a variable picture on ultrasonography. ${ }^{48}$ Therefore the conclusion is still rather uncertain in that the diagnosis of thyroid cancer in patients with HT is subject to many pitfalls and errors, despite advances in technology. The clinicians must use a spectrum of criteria and careful follow-up of the patients for the final diagnosis.

\section{IS PRESENCE OF AUTOIMMUNITY OF PROGNOSTIC VALUE FOR THE OUTCOME OF DIFFERENTIATED THYROID CANCER?}

As mentioned above, thyroid autoimmunity is a very common feature in thyroid carcinoma, encountered in approximately $10-30 \%$ of patients with DTC during follow-up. ${ }^{49-56}$ Serial $\mathrm{TgAb}$ measurements have a prognostic significance for monitoring response to DTC treatment. Patients who have persistent disease after treatment retain detectable $\mathrm{TgAb}$ concentrations ${ }^{49-51,53} \mathrm{~A}$ rise in $\mathrm{Tg} \mathrm{Ab}$ level is often the first indication of recurrence in such patients. ${ }^{52,57-59}$ Although the studies included only a few patients and were mostly of a retrospective design, it seems fair to recommend measurement of serum $\mathrm{TgAb}$ as an adjunct to Tg in the follow-up of DTC. Thus, persistently elevated $\mathrm{TgAb}$ levels appear to serve as a useful marker for recurrent or persistent DTC in patients with undetectable serum thyroglobulin levels while decreasing titers is favourable. Hence the routine measurement of $\mathrm{Tg} \mathrm{Ab}$ in such patients is of great value. ${ }^{57} \mathrm{~A}$ larger study of 226 patients with DTC $^{56}$ found that 51 patients $(22.6 \%)$ of the $\mathrm{Tg}$ undetectable patients showed positive $\mathrm{TgAb}$, and in 25 (49\%) of these recurrence was confirmed. The recurrence rate of $\mathrm{TgAb}$-positive patients was even higher than that of $\mathrm{TgAb}$-negative patients (3.4\%; $p<0.0001)$. During follow-up, $73.1 \%$ of the disease-free patients showed spontaneously decreased $\mathrm{TgAb}$ levels. They further found that a total of $71.4 \%$ of the patients with recurrent cancer, who showed responses to surgical operation or radio-iodine treatment, also demonstrated a decreasing $\mathrm{TgAb}$ level. Their conclusion was that persistently elevated $\mathrm{TgAb}$ levels appeared to serve as a useful marker for recurrent or persistent DTC in patients with undetectable serum $\mathrm{Tg}$ values.

These data strongly suggest that the presence of even small foci of cancer tissue could be sufficient to trigger an autoimmune thyroid disease, such as GD, which might in turn promote cancer relapse. The frequency of this phenomenon is unknown and probably very low. However, the development of GD in patients who had undergone total thyroidectomy may be overlooked in the absence of ophthalmopathy. To our knowledge, no study has evaluated the prevalence of circulating TSAbs in patients with metastatic and/or recurrent thyroid cancer. Further studies are required to assess the impact of persisting or de novo appearance of high titres of TSAbs in patients operated on for thyroid cancer and who had tumour recurrence.

Two studies have shown that thyroid cancer patients expressing $\operatorname{Tg} \mathrm{Ab}$ may have a better prognosis than those without, ${ }^{60,61}$ and Gupta et $\mathrm{a}^{62}$ demonstrated that among 48 children and adolescents with thyroid carcinoma (39 papillary and 9 follicular), those who had a high number of proliferating lymphocytes, demonstrated by the proliferating cell nuclear antigen $\mathrm{Ki}-67$, had a better disease-free survival than those with lower numbers. The finding of a high number of lymphocytes per se did not make any difference. Two other studies have indicated a better prognosis for patients with papillary thyroid cancer in the presence of lymphoid infiltration around the tumour. ${ }^{22,24}$

In a recent retrospective study it was shown that total thyroid ablation resulted in elimination of thyroid autoantibodies though it took in most cases many years. ${ }^{63}$ Theoretically, removal of thyroid tissue takes away inciting antigens and halts antibody production in patients with autoimmune thyroid disease. This retrospective study from a university th yroid disease centre describes 4- to 20-years' follow-up of 182 patients with differentiated thyroid carcinoma 
and thyroid antibodies due to coexistent autoimmune thyroid disease. After thyroidectomy and radioiodine treatment, anti-TPO, TgAb, and TSAbs gradually disappeared in most patients. Gradual disappearance of antibodies suggests that extrathyroidal tissues contribute to antibody production but that continued antibody production depends on persistence of thyroid antigens. Previous studies had been unable to find this effect, probably due to either the investigation of a different patient group, namely Graves' disease and severe eye changes, too short follow-up time, incomplete removal of the thyroid or a combination of these. ${ }^{64}$

Thus, the value of routine measurement of $\mathrm{TgAb}$ in such patient populations now seems substantiated from all of the above studies and speaks in favour of using quantitative measurement of $\mathrm{TgAb}$ in the follow-up of patients with DTC rather than a semiquantitative estimate by, for example, recovery test in the Tg assay. Positive and in particular increasing level of serum $\mathrm{TgAb}$ should lead to a search for metastases or recurrence.

\section{THYROID AUTOIMMUNITY AND SERUM THYROGLOBULIN (TG) AS TUMOUR MARKER}

The most important issue in this connection is the fact that patients with autoimmune thyroid disease very often have $\mathrm{Tg} \mathrm{Ab}$ circulating in their serum, and this interferes in the current methods for measurement of the antigen $\mathrm{Tg}^{1,64-67}$

Although it has previously been considered acceptable to use exogenous $\mathrm{Tg}$ recovery tests to asses interference from $\operatorname{Tg} \mathrm{Ab}$ and thereby also obtain a test for interference from other substances such as heterophilic antibodies or other, ${ }^{68,69}$ it is not generally advised to replace a quantitative measurement of $\operatorname{TgAb}{ }^{1,70-72}$ The Nichols Advantage recovery test ( $\mathrm{TgR}$ assay) may be a valuable complementary method to overcome the technical problem of interference by $\mathrm{TgAbs}$ or heterophilic antibodies in Tg assays. However, further studies are needed to confirm the value of this $\operatorname{TgR}$ assay.

$\mathrm{Tg} \mathrm{Ab}$ interference with immunometric assay (IMA) methodology is always unidirectional (underestimation), while the influence of $\mathrm{Tg} \mathrm{Ab}$ on RIA meas- urements is variable and assay dependent. ${ }^{53}$ Early studies reported that $\operatorname{Tg} \mathrm{Ab}$ caused overestimation of $\mathrm{Tg}$ measured by RIA, presumably when endogenous $\mathrm{TgAb}$ sequestered the tracer. A recent study suggested that Tg RIA measurements were resistant to interference by the low $\mathrm{TgAb}$ concentrations typically seen in TgAb-positive patients with DTC. Because such low $\mathrm{Tg} \mathrm{Ab}$ concentrations were not always detected by current $\mathrm{TgAb}$ assays, RIA methodology appeared to be a more reliable class of assay. However, since few $\mathrm{Tg}$ RIA methods remain available, serial $\mathrm{Tg} \mathrm{Ab}$ concentrations, measured by the same method, may serve as a surrogate antigen ( $\mathrm{Tg}$ ) marker for monitoring DTC patients with circulating $\operatorname{TgAb} .{ }^{53}$

\section{CONCLUSIONS}

In conclusion, thyroid cancer does co-exist with thyroid autoimmunity, and this may have an impact on the management of these patients. Whether radiation may induce both thyroid cancer and autoimmunity is not clear, and for autoimmunity it is probably only relevant in the long-term follow-up. The diagnosis and follow-up of thyroid carcinoma is, however, more difficult with coexisting autoimmunity.

The presence of thyroid autoimmunity may indicate a better prognosis of thyroid carcinoma. Another consequence of the coexistence between thyroid cancer and thyroid autoimmunity is methodological and is related to the use of serum $\mathrm{Tg}$ measurements as tumour marker for relapse or spread of the DTC. Every laboratory should recognise the limitations of the methods used to assess $\operatorname{Tg} \mathrm{Ab}$ interference and clinicians should be aware of the pitfalls of Tg measurements when using serum $\mathrm{Tg}$ as tumour marker in the setting of thyroid autoimmunity. In such cases, serial $\mathrm{Tg} A b$ concentrations by the same method may be a surrogate antigen $(\mathrm{Tg})$ marker for monitoring DTC patients, rise or fall in TgAb indicating recurrence or good outcome, respectively.

\section{REFERENCES}

1. Spencer CA, Takeuchi M, Kazarosyan M, et al, 1998 Serum thyroglobulin autoantibodies: Prevalence, influence on serum thyroglobulin measurement, and prognostic significance in patients with differentiated thyroid carcinoma. J Clin Endocrinol Metab 83: 1121- 
1127.

2. Pacini F, Schlumberger M, Dralle H, et al, and the European Thyroid Cancer Taskforce 2006 European consensus for the management of patients with differentiated thyroid carcinoma of the follicular epithelium. Eur J Endocrinol 154: 787-803

3. Cooper DS, Doherty GM, Haugen BR, et al, The American Thyroid Association Guidelines Taskforce 2006 Management guidelines for patients with thyroid nodules and differentiated thyroid cancer. Thyroid 16: 109-142.

4. Dailey ME, Lindsay S, Skahen R, 1955 Relation of thyroid neoplasms to Hashimoto disease of the thyroid gland. AMA Arch Surg 70: 291-297.

5. Pollock WF, Sprong DH, 1958 The rationale of thyroidectomy for Hashimoto's thyroiditis: a premalignant lesion. West J Surg Obstet Gynecol 66: 17-20.

6. Meier DW, Woolner LB, Beahrs OH, McConahey WM, 1959 Parenchymal findings in thyroidal carcinoma: pathologic study of 256 cases. J Clin Endocrinol 19: 162-171.

7. Woolner LB, McConaley WM, Beahrs OH, 1959 Struma lymphomatosa (Hashimoto's thyroiditis) and related thyroidal disorders. J Clin Endocrinol Metab 19: 5358.

8. Schlicke CP, Hill JE, Schultz GF, 1960 Carcinoma in chronic thyroiditis. Surg Gynecol Obstet 111: 552 556.

9. Shands WC, 1960 Carcinoma of the thyroid in association with struma lymphomatosa. Ann Surg 151: 675-682.

10. Chesky VE, Hellwing CA, Welch JW, 1962 Cancer of the thyroid associated with Hashimoto's disease: an analysis of forty-eight cases. Am Surg 28: 678-685.

11. Crile G Jr, Hazard JB, 1962 Incidence of cancer in struma lymphomatosa. Surg Gynecol Obstet 115: 101-103.

12. Hirabayashi RN, Lindsay S, 1965 The relation of thyroid carcinoma and chronic thyroiditis. Surg Gynecol Obstet 121: 243-252.

13. Holmes HB, Kreutner A, O‘Brien PH, 1977 Hashimoto’s thyroiditis and its relationship to other thyroid diseases. Surg Gynecol Obstet 144: 887-890.

14. Figg DM, Bratt HJ, van Vliet PD, Dean RE, 1978 Thyroid cancer: diagnosis and management based on a review of 142 cases. Am J Surg 135: 671-674.

15. Ott RA, Calandra DB, McCall A, Shah KH, Lawrence AM, Paloyan E, 1985 The incidence of thyroid carcinoma in patients with Hashimoto's thyroiditis and solitary cold nodules. Surgery 98: 1202-1206.

16. Ott RA, McCall AR, McHenry C, et al, 1987 The incidence of thyroid carcinoma in Hashimoto's thyroiditis. Am Surg 53: 442-445.

17. Eisenberg BL, Hensley SD, 1989 Thyroid cancer with coexistent Hashimoto's thyroiditis. Arch Surg 124: 1045-1047.

18. McKee RF, Krukowski ZH, Matheson NA, 1993 Thyroid neoplasia coexistent with chronic lymphocytic thyroiditis. Br J Surg 80: 1303-1304.

19. Sclafani AP, Valdes M, Cho H, 1993 Hashimoto's thyroiditis and carcinoma of the thyroid: optimal management. Laryngoscope 103: 845-849.

20. Okayasu I, Fujiwara M, Hara Y, Tanaka Y, Rose NR, 1995 Association of chronic lymphocytic thyroiditis and thyroid papillary carcinoma. A study of surgical cases among Japanese and white and African Americans. Cancer 76: 2312-2318.

21. Schäffler A, Palitzsch KD, Seiffarth C, et al, 1998 Coexistent thyroiditis is associated with lower tumours stage in thyroid carcinoma. Eur J Clin Invest 28: 838-844.

22. Loh KC, Greenspan FS, Dong F, Miller TR, Yeo PP, 1999 Influence of lymphocytic thyroiditis on the prognostic outcome of patients with papillary thyroid carcinoma. J Clin Endocrinol Metab 84: 458-463.

23. Singh B, Shaha AR, Trivedi H, Carew JF, Poluri A, Shah JP, 1999 Coexistent Hashimoto's thyroiditis with papillary thyroid carcinoma: impact on presentation, management, and outcome. Surgery 126: 1070-1077.

24. Kebebew E, Treseler PA, Ituarte PHG, Clark OH, 201 Coexisting chronic lymphocytic thyroiditis and papillary thyroid cancer revisited. World J Surg 25: 632-637.

25. Tamimi DM, 2002 The association between chronic lymphocytic thyroiditis and thyroid tumors. Int J Surg Pathol 10: 141-146.

26. Cipolla C, Sandonato L, Graceffa G, et al, 2005 Hashimoto thyroiditis coexistent with papillary thyroid carcinoma. Am Surg 71: 874-878.

27. Kurukahvecioglu O, Taneri F, Yóksel O, Aydin A, Tezel E, Onuk E, 2007 Total thyroidectomy for the treatment of Hashimoto's thyroiditis coexisting with papillary thyroid carcinoma. Adv Ther 24: 510-516.

28. Wirtschafter A, Schmidt R, Rosen D, et al, 1997 Expression of the RET/PTC fusion gene as a marker of papillary carcinoma in Hashimoto's thyroiditis. Laryngoscope 107: 95-100.

29. Unger P, Ewart M, Wang BY, Gan L, Kohtz DS, Burstein DE, 2003 Expression of p63 in papillary thyroid carcinoma and in Hashimoto's thyroiditis: a pathobiologic link? Hum Pathol 34: 764-769.

30. Larson SD, Jackson LN, Riall TS, et al, 2007 Increased incidence of well-differentiated thyroid cancer associated with Hashimoto's thyroiditis and the role of the PI3k/Akt pathway. J Am Coll Surg 204: 764-763.

31. Arif S, Blanes A, Diaz-Cano SJ, 2002 Hashimoto's thyroiditis share features with early papillary thyroid carcinoma. Histopathology 41: 357-362.

32. Belfiore A, Russo D, Vigneri R, Filetti R, 2001 Graves' disease, thyroid nodules and thyroid cancer. Clin Endocrinol 55: 711-718.

33. Rasmussen AK, Feldt-Rasmussen U, Bendtzen K, 1993 The effect of interleukin-1 on the thyroid gland. Autoimmunity 16: 765-769.

34. Boelaert K, Horacek J, Holder RL, Watkinson JC, Sheppard MC, Franklyn JA, 2006 Serum thyrotropin 
concentration as a novel predictor of malignancy in thyroid nodules investigated by fine-needle aspiration. J Clin Endocrinol Metab 91: 4295-4301.

35. Williams ED, 2006 Chernobyl and thyroid cancer. J Surg Oncol 94: 670-677.

36. Vykhovanets EV, Chernyshov VP, Slukvin II, et al, 1997 131I dose-dependent thyroid autoimmune disorders in children living around Chernobyl. Clin Immunol Immunopathol 84: 251-259.

37. Tronko MD, Brenner AV, Olijnyk VA, et al, 2006 Autoimmune thyroiditis and exposure to iodine 131 in the Ukrainian cohort study of thyroid cancer and other thyroid diseases after the Chornobyl Accident: Results from the first screening cycle (1998-2000). J Clin Endocrinol Metab 91: 4344-4351.

38. Pacini F, Vorontsova T, Molinaro E, et al, 1998 Prevalence of thyroid autoantibodies in children and adolescents from Belarus exposed to the Chornobyl radioactive fallout. Lancet 352: 763-766.

39. Vermiglio F, Castagna MG, Volnova E, et al, 1999 Post-Chernobyl increased prevalence of humoral thyroid autoimmunity in children and adolescents from a moderately iodine-deficient area in Russia. Thyroid 9: 781-786.

40. Shinkarkina AP, Podgorodnichenko VK, Poverennyi AM, 1994 Antibodies to the thyroid microsomal antigen in children and adolescents subjected to radiation exposure as a result of the accident at the Chernobyl Atomic Electric Power Station. Radiats Biol Radioecol 34: 3-7.

41. Imaizumi M, Usa T, Tominaga T, et al, 2006 Radiation dose-response relationships for thyroid nodules and autoimmune thyroid diseases in Hiroshima and Nagasaki atomic bomb survivors 55-58 years after radiation exposure. JAMA 295: 1011-1022.

42. Vanderpump MP, Tunbridge WM, French JM, et al, 1995 The incidence of thyroid disorders in the community: a twenty-year follow-up of the Whickham Survey. Clin Endocrinol (Oxf) 43: 55-68.

43. Volzke H, Werner A, Wallaschofski H, et al, 2005 Occupational exposure to ionising radiation is associated with autoimmune thyroid disease. J Clin Endocrinol Metab 90: 4587-4592.

44. Davis S, Kopecky KJ, Hamilton TE, Onstad L, 2004 Thyroid neoplasia, autoimmune thyroiditis, and hypothyroidism in persons exposed to iodine 131 from the Hanford nuclear site. JAMA 292: 2600-2613.

45. Boi F, Lai ML, Marziani B, Minerba L, Faa G, Mariotti S, 2005 High prevalence of suspicious cytology in thyroid nodules associated with positive thyroid autoantibodies. Eur J Endocrinol 153: 637-642.

46. Baker JR Jr, 1995 The immune response to papillary thyroid cancer. J Clin Endocrinol Metab 80: 34193420.

47. Kollur SM, El Sayed S, El Hag A, 2003 Follicular thyroid lesions coexisting with Hashimoto's thyroiditis:
Incidence and possible sources of diagnostic errors. Diagn Cytopathol 28: 35-38.

48. Ohmori N, Miyakawa M, Ohmori K, Takano K, 2007 Ultrasonographic findings of papillary thyroid carcinoma with Hashimoto's thyroiditis. Intern Med 46: 547-550.

49. Pacini F, Mariotti S, 1988 Thyroid autoantibodies in thyroid cancer: incidence and relationship with tumour outcome. Acta Endocrinol 119: 373-380.

50. Rubello D, Girelli ME, Casaro D, Piccolo M, Perin A, Busnardo B, 1990 Usefulness of the combined antithyroglobulin antibodies and thyroglobulin assay in the follow-up of patients with differentiated thyroid cancer. J Endocrinol Invest 13: 737-742.

51. Rubello D, Casara D, 1992 Clinical meaning of circulating ATG in differentiated thyroid cancer: a prospective study. J Nucl Med 33: 1478-1480.

52. Kumar A, Shah DH, Shrihari U, Dandekar SR, Viyojan U, Sharma SM, 1994 Significance of anti-Tg autoantibodies in differentiated thyroid carcinoma. Thyroid 4: 199-202.

53. Spencer CA, Bergoglio LM, Kazarosyan M, Fatemi S, LoPresti JS, 2005 Clinical Impact of Thyroglobulin (Tg) and Tg Autoantibody Method Differences on the Management of Patients with Differentiated Thyroid Carcinomas. J Clin Endocrinol Metab 90: 5566-5575.

54. Feldt-Rasmussen U, Holten I, Hansen HS, 1983 Influence of thyroid substitution therapy and thyroid autoantibodies on the value of serum thyroglobulin in recurring thyroid cancer. Cancer 51: 2240-2244.

55. Hjiyiannakis P, Mundy J, Harmer C, 1999 Thyroglobulin antibodies in differentiated thyroid cancer. Clin Oncol 11: 240-244.

56. Chung J-K, Park Y J, Kim T Y, et al, 2002 Clinical significance of elevated level of serum antithyroglobulin antibody in patients with differentiated thyroid cancer after thyroid ablation. Clin Endocrinol 57: 215-221.

57. Larbre H, Schvartz C, Schneider N, et al, 2000 Positive antithyroglobulin antibodies in patients with differentiated thyroid carcinoma. What significance? Ann Endocrinol (Paris) 61: 422-427.

58. Kücük ÖN, Aras G, Kulak HA, Ibis E, 2006 Clinical importance of anti-thyroglobulin auto-antibodies in patients with differentiated thyroid carcinoma: Comparison with 99mTc-MIBI scans. Nucl Med Commun 27: 873-876.

59. Whitley RJ, Ain KB, 2004 Thyroglobulin: a specific serum marker for the management of thyroid carcinoma. Clin Lab Med 24: 29-47.

60. Baker JR, Fosso CK, 1993 Immunological aspects of cancers arising from thyroid follicular cells. Endocr Rev 14: 729-746.

61. Souza SL, Montalli da Assumpção LV, Ward LS, 2003 Impact of Previous Thyroid Autoimmune Diseases on Prognosis of Patients with Well-Differentiated Thyroid Cancer. Thyroid 13: 491-495. 
62. Gupta S, Patel A, Folstad A, et al, 2001 Infiltration of Differentiated Thyroid Carcinoma by Proliferating Lymphocytes Is Associated with Improved DiseaseFree Survival for Children and Young Adults. J Clin Endocrinol Metab 86: 1346-1354.

63. Chiovato L, Latrofa F, Braverman LE, et al, 2003 Disappearance of humoral thyroid autoimmunity after complete removal of thyroid antigens Ann Intern Med 139: 346-351.

64. Feldt-Rasmussen U, 1983 Serum thyroglobulin and thyroglobulin autoantibodies in thyroid diseases. Pathogenic and diagnostic aspects. Allergy 38: 369-387.

65. Mariotti S, Barbesino G, Caturegli P, 1995 Assay of thyroglobulin in serum with thyroglobulin autoantibodies: an unobtainable goal? J Clin Endocrinol Metab 80: 468-472.

66. Feldt-Rasmussen U, Schlumberger M, 1988 European interlaboratory comparison of serum thyroglobulin measurement. J Endocrinol Invest 11: 175-181.

67. Feldt-Rasmussen U, Rasmussen AK, 1985 Serum thyroglobulin $(\mathrm{Tg})$ in presence of thyroglobulin autoantibodies (TgAb). Clinical and methodological relevance of the interaction between $\mathrm{Tg}$ and $\mathrm{TgAb}$ in vitro and in vivo. J Endocrinol Invest 8: 571-576.
68. Schaadt B, Feldt-Rasmussen U, Rasmusson B, 1995 Assessment of the influence of thyroglobulin ( $\mathrm{Tg}$ ) autoantibodies and other interfering factors on the use of serum $\mathrm{Tg}$ as tumor marker in differentiated thyroid carcinoma. Thyroid 5: 165-170.

69. Persoon ACM, Link TPs, Wilde J, Sluite WJr, Wolffenbuttel BHR, JMW van den Ouweland, 2006 Thyroglobulin (Tg) Recovery Testing with Quantitative Tg Antibody Measurement for Determining Interference in Serum Tg Assays in Differentiated Thyroid Carcinoma. Clin Chem 52: 1196-1199.

70. Laboratory support for the diagnosis and monitoring of thyroid disease. National Academy of Clinical Biochemistry - Professional Association 2002. http://www. nacb.org

71. Massart C, Maugendre D, 2002 Importance of the Detection Method for Thyroglobulin Antibodies for the Validity of Thyroglobulin Measurements in Sera from Patients with Graves' Disease. Clin Chem 48: 102-107.

72. Spencer CA, 1996 Recoveries cannot be used to authenticate thyroglobulin ( $\mathrm{Tg}$ ) measurements when sera contain Tg autoantibodies. Clin Chem 42: 661-663. 